\title{
Parental Perception of Skills in Children with Autism Spectrum Disorders and the Relationship to Transition Processes
}

\author{
Alfa Celene Rea-Amaya, Guadalupe Acle-Tomasini, Gabriela Ordaz-Villegas \\ Facultad de Estudios Superiores Zaragoza, Universidad Nacional Autónoma de México, México City, México \\ Email: celenere1982@hotmail.com,gaclet@unam.mx,gabriela.ordazvillegas@yahoo.com.mx
}

How to cite this paper: Rea-Amaya, A. C., Acle-Tomasini, G., \& Ordaz-Villegas, G. (2019). Parental Perception of Skills in Children with Autism Spectrum Disorders and the Relationship to Transition Processes. Psychology, 10, 1333-1351.

https://doi.org/10.4236/psych.2019.109085

Received: May 15, 2019

Accepted: July 20, 2019

Published: July 23, 2019

Copyright $\odot 2019$ by author(s) and Scientific Research Publishing Inc. This work is licensed under the Creative Commons Attribution International License (CC BY 4.0).

http://creativecommons.org/licenses/by/4.0/

\begin{abstract}
The process of transition between different developmental stages gains specific importance for individuals with ASD. Parents of children with ASD will face the challenge of guiding this transition both during the stages of physical and psychological development, and academic and occupational phases. The purpose of this study was to examine the parental perception of skills development in children with ASD and the relationship to perceived elements required to transition between different developmental stages. This descriptive, non-experimental, cross-sectional, and correlational study included 32 participants, the parents of ASD diagnosed children (aged between 3 and 22 years). Participants ranged in age from 22 to 52 years; $84.4 \%$ of them were women. Main findings: The perception from most participants emphasizes poor ability in children, regardless of developmental stage, to communicate or express emotions, which is translated into poor school-related and social skills performance. The fact that overall parents believe that their children are dependent and will require assistance from them or other people to perform everyday activities in the social, school, and family settings is highlighted as well. Depending on the child's stage of development, parents express different expectations matching their children's own development. Parents expect their children to grow up to be independent in certain aspects, as children develop more self-care skills with increase in age. However, most parents perceive that the prospects of a promising future for their children will be limited by children's poor skills.
\end{abstract}

\section{Keywords}

Autism Spectrum Disorder, Transition, Language Skills, Future, Educational Aspirations 


\section{Introduction}

The World Health Organization (WHO, 2017) estimates that 1 in 162 children has an Autism Spectrum Disorder (ASD). This estimate, however, is an average, and prevalence may vary depending on the study conducted. Epidemiological studies have observed a prevalence increase of ASD in children over the last 50 years. In the case of Mexico, a study conducted by Fombonne et al. (2016) found that 1 in 115 children has an ASD, as observed in a sample of children in elementary school from the state of Guanajuato. However, this prevalence is not to be considered representative of the rest of the country.

The Diagnostic and Statistical Manual of Mental Disorders (DSM-5) describes that an ASD diagnosis requires children to present symptoms during the early development period that cause clinically significant impairment in social, occupational, or other important areas of current functioning. These symptoms include: 1) persistent deficits in social communication and interaction across multiple contexts; deficits in socio-emotional reciprocity; exhibiting abnormal nonverbal communicative behaviors in social interaction; deficits in developing, maintaining, and understanding relationships, such as difficulties adjusting behavior to suit various social contexts, difficulties in imaginative play and making friends, or showing no interest in other people; 2) restrictive and repetitive patterns of behavior, interests, or activities, such as stereotyped or repetitive movements, use of objects, or speech; excessively rigid routines, or ritualized patterns of verbal and nonverbal behavior; highly restricted and fixed interests that are uncommonly intense; and hyper-or hyposensitivity to sensory input, or unusual interest in sensory aspects of the environment (American Psychiatric Association, 2014).

These characteristics limit the ability of individuals with ASD to do daily activities and the way they interact with others, affecting educational milestones and employability. Individuals with ASD, depending on their characteristics, may become independent or need constant support and care throughout their lives, the latter potentially being a situation of significant emotional and economic burden to their families (WHO, 2017). Aspects related to lack of independence are associated with impairments in social skills, language skills, and routine, organization, and attention skills, as well as emotional expressiveness, i.e. skills that are essential to daily living. Moreover, it is important to identify the academic and self-care activities that children with ASD can perform, because parents being able to recognize these skills in their children will be relevant to promote transition processes between different developmental stages.

Transition refers to seeing changes as they occur between human developmental stages, each one of which involves different challenges related to what is expected in a given culture (Masten \& Powell, 2007). In this sense, parents of children with ASD will face the challenge of guiding this transition both during the stages of physical and psychological development, and academic and later occupational phases. This involves supporting their children during the stages of 
development, from childhood to adolescence, and from adolescence to adulthood, as well as the transition between school phases, from preschool/kindergarten to elementary school, from elementary school to middle school, from middle school to high school, and then from high school to postsecondary education and, eventually, employment. Many studies have reported that parents of children with ASD face every stage with fear, stress, and emotional problems. They perceive these transitions as big challenges, and do not feel prepared to overcome them. Also, communication with professionals is insufficient, as the latter do not consider the information that parents may provide about their own children for transition between school phases, and support given during transition is not adequate. Parents also exhibit poor well-being, confusion about transition, and anxiety about their children's ability to meet social and academic demands (Begeer et al., 2017; Makin, Hill, \& Pellicano, 2017; Mandy et al., 2016; Miller-Warren, 2016; Quint, 2014; Sproston, Sedgewick, \& Crane, 2017; Stoner, Angell, House, \& Bock, 2007; Tobin et al., 2012; Weiss et al., 2014, Wehman et al., 2014).

Welchons and McIntyre (2015) explain that kindergarten transition is a critical early developmental milestone during childhood. They consequently explore family and teacher concerns and involvement in said transition for children with disabilities from the United States. Authors reported that teachers facilitated communication between school and home. Similarly, caregiver and teacher involvement were higher for children with disabilities. Authors found that teacher transition practices were highly related to preschoolers' behavior-i.e. higher teacher involvement in transition activities was associated with poorer child socio-behavioral competencies. Authors differentiated between preschool and kindergarten teachers, and reported that, by individualizing transition intervention efforts, preschool teachers were able to meet children's and families' needs, while kindergarten teachers only implemented a similar set of transition activities. Also, authors found that families of children with disabilities reported more overall and specific concerns about transition from preschool to kindergarten than families with children without disabilities. Both US American family groups, nevertheless, reported concerns about their children's separation from family in order to go to school.

Quintero and McIntyre (2011) investigated teacher concerns in schools in the United States, as well as teacher and family experiences related to kindergarten transition practices for children with ASD and children with other delays or disabilities. Authors found that teachers expressed overall more transition-related concerns for children with ASD than for children with other disabilities. Parent involvement in transition preparation activities did not differ among parents of children with ASD and parents of children with other disabilities. Parents were asked about teacher involvement in transition activities and reported higher preschool teacher involvement. Authors suggest that although parent and teacher involvement in transition preparation was high, practices were rarely indivi- 
dualized.

By analyzing the primary-to-secondary school transition for English children with ASD and examining the factors that contribute to a successful school transition, Makin et al. (2017) observed that children reported negative experiences related to school choice, delays in placement decisions, lack of adequate academic preparation from elementary school, and lack of communication between schools. Equally, Mandy et al. (2016) found that during primary-to-secondary school transition of British students with ASD, high levels of psychopathology and school maladjustment were persistent. However, bullying by peers was found to decrease from primary to secondary school.

Adreon and Stella (2001) similarly explain that the transition from elementary school to secondary school is marked by multiple changes in the school setting, including larger school size, more rigorous grading policies, more academic subjects and, consequently, increased workload. Characteristics typical of students with ASD, such as deficits in interaction, communication, and adjustment, substantially affect transition processes, thus representing a higher risk of adjustment problems and requiring extremely careful transition planning. Authors propose some pre-transition activities, such as transition planning meetings, better training for teachers and guidance for students, which combined with appropriate accommodations and adaptations may increase the likelihood of a successful transition and school year for youth with ASD.

Regarding the transition to secondary school for adolescent girls with ASD, Sproston et al. (2017) explain that it is advisable to explore in which way mainstream English schools are flexible in their practices, and ensure teacher specialization in disability issues to achieve a successful inclusion; and highlight the importance of principals promoting positive inclusion attitudes and thus instilling them in teachers. Authors emphasize that it is essential to establish positive relationships with the families of children with autism to help relieve the burden and access their knowledge about the children. In this sense, Miller-Warren (2016) studied parental perceptions of the transition process from middle school to high school for children with disabilities in the United States, and found that this process was not successful for parents, who considered that the transition planning process in middle school did not positively influence children's high school outcomes.

Alverson, Lindstrom, and Hirano (2015) interviewed young adults aged between 19 and 22 years with a diagnosis of Asperger syndrome, their families, secondary school teachers, and support staff to identify the personal and contextual barriers young adults with Asperger syndrome faced in postsecondary education and what transition services they needed to be prepared for it. Authors concluded that their social, communication, and executive functioning skills posed challenges during secondary education and into college, and that such barriers could limit their ability to deal with academic workload, as well as their involvement in social activities associated with postsecondary education. Authors identified that a successful transition from secondary education to col- 
lege was influenced by the source of motivation to go to college, high levels of disability awareness, intentional family support, coordinated transition planning, and clear postsecondary education goals.

In Mexico's school context, parents of children with ASD in elementary school believed that a significant risk factor was that teachers were not qualified to assist children in school. Thus, however continually mentioned in the official discourse, education inclusion as outlined by the Mexican Government was not being achieved. Parents were aware that children had not developed the required skills to perform well academically, such as reading and writing. This, combined with children's difficulties to develop relationships, led parents to have more concerns about what their children could achieve in the future, and fears about the very thought of what would happen when they will no longer be there to assist their children. This left families in vulnerability situations for next transition processes during development and education (Rea-Amaya \& Acle-Tomasini, 2017b).

In this sense, Jurado de los Santos and Bernal (2013) report that, when reaching adulthood and leaving school settings behind, transition processes for youth with disabilities have had a positive evolution, in that equal social involvement is gradually accessed, as plans for adapting and making those processes flexible to the needs of individuals with ASD are currently being put into place. This access to and involvement in social life is ultimately aimed at improving the quality of life. Nonetheless, many studies show that this is not always the case. An assessment of the quality of life for adults with ASD ranging in age from 18 to 28 years, and the relationship to self-regulation skills in the Netherlands, conducted by Dijkhuis, Ziermans, Van Rijn, Staal, and Swaab (2016), found that adults with ASD showed poorer quality of life and more deficits in processing emotions and daily executive functioning, compared to adults without a diagnosis of ASD.

By analyzing the main transition sequences to adulthood and employment for US American individuals with ASD in the six years after high school exit, and their demographics and functioning associated with different transition sequences, Wei, Wagner, Hudson, Yu, and Shattuck (2015) in turn reported a preoccupying scenario for youth with ASD in the United States, since transition activities from school to adult life were insufficient for them to be able to continue to study or to get a job. Authors also found disproportionate transition patterns by gender, family income, functional cognitive skills, and conversational skills.

In relation to the role of family in transition processes, King et al. (2006) found that in Canada, families overcame difficulties related to children with disabilities by building upon their own values, regarded as fundamental operational principles with which individuals run their lives and organize family living, including open communication and group family activities. Authors concluded that parents could give a sense of consistency and control if they changed their own thoughts on their children with disabilities. Consequently, they could make positive adaptations when they were able to modify their views on life and 
disability and become aware that their children positively contributed to themselves and family members over time.

In Mexico, Rea-Amaya and Acle-Tomasini (2017b) analyzed the resilient strategies and behaviors that parents of children with ASD exhibit under the different vulnerability situations they have faced from children's birth forth. The study reported that risk and protective factors are closely correlated in a dynamic way. Parents reported to exhibit escape and distress behaviors in the face of vulnerability situations due to having a child with ASD. However, they also exhibited skills, such as self-efficacy, seeking information, and social support, to overcome the many problems that a child with disability faces from birth and during development. Self-efficacy allowed parents to deal with their children's disabilities, and to overvalue what children could achieve or not, and therefore begin to develop skills that could help adjustment to the environment. This study also found risk factors for parents, including overprotection of children with ASD; negative emotions, such as sadness, solitude, distress; concerns at the moment of diagnosis, and not knowing how to interact with the child and react to inappropriate behavior in social contexts.

Therefore, the importance of the role that parents play in understanding skills in their children with ASD, and the relationship to transition processes during development, is highlighted. And the purpose of this study is to analyze parental perceptions of skills development in children with ASD, including the areas of language; routine, organization, and attention; academic activities; emotional expressiveness; social skills; and self-care, and how these are related to the perception of the elements required for developmental transition.

\section{Method}

\subsection{Participants}

Non-probabilistic purposive sampling was used. Parents who have children with a diagnosed Autism Spectrum Disorder (ASD) were sampled.

The sample included 32 primary caregivers, 26 of which were identified as the mothers, 5 the fathers, and 1 the aunt, 27 being female (84.4\%) and 5 being male $(15.6 \%)$. The sample ranged in age from 22 to 52 years (mean age $=40.35 ; S E=$ 6.55). Table 1 shows the participants' level of education. Women's occupation was identified as 14 of them doing domestic work (45.2\%) and 12 doing other work activities (38.7\%). For men, all 5 of them (100\%) reported being full-time workers.

Table 1. Parental level of education in percentage.

\begin{tabular}{cc}
\hline Level of education & Percentage \\
\hline High school/Technical degree & 19.4 \\
Undergraduate degree & 67.7 \\
Postgraduate degree & 12.9 \\
Total & 100 \\
\hline
\end{tabular}


Children with ASD were 3 females (9.4\%) and 29 males (90.6\%). Their age ranged from 3 to 22 years (mean age $=9.44 ; S E=4.51$ ). Four groups were identified: 1 ) preschoolers from 3 to 5 years; 2) grade schoolers from 6 to 11 years; 3 ) teens from 12 to 14 years, and 4 ) young adults from 21 to 22 years (Table 2).

\subsection{Instruments}

- Perception of skills in children with Autism Spectrum Disorders Scale-Parent version (Rea-Amaya \& Acle-Tomasini, 2016). It aims at reporting parental perception of development and performance of children's skills in different areas. It is a paper-and-pencil instrument comprised of 71 items organized into the following aspects: language skills (11), routine, organization, and attention (10); academic activities (10); emotional expressiveness (13); social skills (9), and self-care (18). Parents or primary caregivers were asked to complete the 71 items, each offering 5 category response options: $1=$ never; 2 = seldom; $3=$ sometimes; $4=$ most of the time, and $5=$ always. It can be either group or individually administered. Before administration, validity was assessed by expert judges in the field, and $95 \%$ of agreement was obtained.

Definition of studied skills:

1) Language skills: Ability to understand and verbally use words in context.

2) Routine, organization, and attention: Routine-Habits for doing something in a specific way, which does not require thinking or decision-making. Organization-A methodological action a person does to obtain a specific goal. Attention-The behavioral and cognitive process of focusing on a specific stimulus or object.

3) Academic activities: A set of operations and tasks in the school environment that are scheduled by teachers and students, and done individually or in group, in and out classroom, in order to meet educational goals.

4) Emotional expressiveness: The way in which the child expresses, hides, or regulates diverse affective reactions. Emotion is an internal experience that is only expressed externally through gestures and movements.

5) Social skills: The behaviors a person exhibits in the social context to be able to express emotions, feelings, desires, rights, etc. in an appropriate way, respecting others' opinion or behaviors.

Table 2. Groups of children with ASD by age range.

\begin{tabular}{cccc}
\hline Level of education & Age range in years & $\mathrm{n}$ & $\%$ \\
Group 1 & $3-5$ & 6 & 18.80 \\
Group 2 & $6-11$ & 18 & 56.30 \\
Group 3 & $12-14$ & 6 & 6.30 \\
Group 4 & $21-22$ & 2 & 100.00 \\
Total & $3-22$ & 32 & \\
\hline
\end{tabular}


6) Self-care: Skills related to washing, eating, dressing, and personal hygiene, and physical appearance.

- Perception of transition-related elements in children with Autism Spectrum Disorders Scale-Parent version (Rea-Amaya \& Acle-Tomasini, 2017a). It aims at obtaining parental perception of the elements that are deemed necessary to deal with children's transition processes between different developmental stages. It is a paper-and-pencil instrument comprised of 60 items related to the following areas: dependence (14), independence (11), educational aspirations (7), school experiences (15), social impact (6), and the future of children with ASD (7). Parents or primary caregivers were asked to complete the 60 items, each offering 5 category response options: $1=$ never; $2=$ seldom; $3=$ sometimes; $4=$ most of the time, and $5=$ always. It can be either group or individually administered. Before administration, validity was assessed by expert judges in the field, and $95 \%$ of agreement was obtained.

Definition of the analyzed transition-related areas:

1) Independence: The functional ability to perform daily life activities. It is the ability to act, make decisions and fend for oneself, and taking responsibility.

2) Dependence: The mental or physical state of a person in need of specific support by others to complete activities that allows a feeling of well-being, even in a nonoptimal situation for fending for oneself, or in the absence of autonomy.

3) Educational aspirations: The desires and expectations parents of children with ASD have about their children achieving school or grade level milestones.

4) School experience: The daily experiences that children with ASD have in school.

5) Social impact: A very strong impression or effect on parents of children with ASD due to their children's disabilities.

6) Future: The circumstances or behaviors that parents help develop will present as their children with ASD grow older, and the expectations parents have about their children for the years to come.

\subsection{Procedure}

This is a descriptive, non-experimental, cross-sectional, and correlational study intended to analyze a phenomenon as it occurs in its own setting at a given moment. Population characteristics are described, differences among observed factors are analyzed in said population, and correlations are drawn to make associations (Kerlinger \& Lee, 2002; Shaughnessy, Zechmeister, \& Zechmeister, 2007).

Appropriate paperwork was completed to be allowed to help a private association created by parents of children with ASD. Both parents were invited to participate through the social network of the association. They were first verbally explained the purpose of this study and what their participation in it would consist of. Confidentiality and global use of collected data to the purpose of the study were emphasized. Then, they were individually given a consent form, for them to read and sign. Finally, the instruments were group administered during sessions of approximately 50 minutes. 


\subsection{Data Analysis}

Data obtained from scales were analyzed by using the SPSS Version 21, which yielded descriptive analysis. Nonparametric statistics were used in the form of Spearman's correlation to make associations, and a Kruskall-Wallis test, together with a Mann-Whitney $U$ test, was conducted to test for differences.

\section{Results}

With the purpose of obtaining parental perceptions of skill development in children with ASD, the results obtained were analyzed by age group and skills as follows: language skills; routine, organization, and attention; academic activities; emotional expressiveness; social skills, and self-care. Selection frequency is described below, with an emphasis made on extreme scores, as these allow a more accurate identification of parental perception of multiple skills.

Regarding language skills and regardless of children's age, most parents (21) perceived that their children have poor ability to understand and use words, even though more than $50 \%$ of sampled children were 6 years or older. In contrast, only 5 parents reported that their children have always exhibited this ability. On the other hand, it is worth mentioning that one parent from Group 1 did not complete items related to this area, since the child still had not developed language.

As for skills related to routine, organization, and attention, most parents (23) perceived that their children, regardless of age, do not master habits, methodological organization, or attention needed to perform daily activities. Few parents (5) reported that their children had developed these skills. However, it is important to note that parents perceived that their children gain more maturity and perform better with increase in age.

Another area that was key to examine was parental perception of performance in activities in the school setting. As an example of the way that scores were distributed in Table 3 it can be seen that most of parents (18) reported that their children, regardless of age, did not do the usual schoolwork, thus school grade level academic objectives were not attained. On the other hand, only 8 parents across age groups were identified to perceive that their children always use skills necessary to an adequate performance in the school context, including writing,

Table 3. Parent-perceived performance in academic activities by children age group.

\begin{tabular}{|c|c|c|c|c|c|c|c|}
\hline & $\begin{array}{l}\text { Age of children } \\
\text { with ASD }\end{array}$ & $\mathrm{n}$ & Never & Seldom & Sometimes & $\begin{array}{l}\text { Most of } \\
\text { the time }\end{array}$ & Always \\
\hline Group 1 & $3-5$ & 3 & 2 & 0 & 0 & 0 & 1 \\
\hline Group 2 & $6-11$ & 18 & 5 & 3 & 3 & 3 & 4 \\
\hline Group 3 & $12-14$ & 6 & 1 & 1 & 1 & 1 & 2 \\
\hline Group 4 & $21-22$ & 2 & 0 & 1 & 0 & 0 & 1 \\
\hline Total & & 29 & 8 & 5 & 4 & 4 & 8 \\
\hline
\end{tabular}


reading, and solving mathematical problems-i.e. skills development to adequately perform may be promoted. Parent, teacher, and child interventions must be investigated to achieve this. It is worth mentioning that 3 parents did not complete this section since their children are too young to go to school.

Emotional expressiveness is a fundamental part in communication between people, which is not exception for children with ASD. In this area, most parents (24) were observed to perceive that their children, regardless of age, inadequately express their emotions. Only 3 parents reported that their children can always use expected emotional expressions-from identifying others' emotions to expressing their own emotions through gestures and movements, including laugh, and crying-and emotional self-regulatory skills-including tantrum and crisis control, as well as stress or anxiety. As seen in Table 4, the above findings are related to parental perception of children's social skills as they reported it: the younger the children, the more insufficient parents believe their children's ability is to exhibit expressiveness-related behaviors in social contexts, such as family and friends-including being unable to express emotions, feelings, and desires in an appropriate way, respecting others' opinions and behaviors. Similarly, 11 parents in Group 2 and 3 in Group 3 also reported these deficits in their children, unlike parents in Group 4, whose children are young adults. However, it may be highlighted that although parents believe that their children, regardless of age, are developing skills in this area, most parents acknowledge that deficits in social skills persist in their children, due to characteristics typical to them, as reported in the literature on individuals with ASD.

It was revealed that parental perception of self-care in their children follows a pattern related to what is expected for their children's age-i.e. the younger the child, the more inclined responses are towards options related to the development of self-care skills. 14 parents reported that their children have developed these skills. On the other hand, 13 parents believed that their children, regardless of age, possess necessary self-care skills, such as personal hygiene, from washing, dressing, and brushing their teeth to daytime and nighttime sphincter control, as well as eating activities_-including self-feeding, -serving and -preparing, using electrical appliances, and even going grocery shopping, and satisfying their eating needs.

Table 4. Parent-perceived performance in social skills by children age group.

\begin{tabular}{cccccccc}
\hline & $\begin{array}{c}\text { Age of children } \\
\text { with ASD }\end{array}$ & $\mathrm{n}$ & Never & Seldom & Sometimes & $\begin{array}{c}\text { Most of } \\
\text { the time }\end{array}$ & Always \\
\hline Group 1 & $3-5$ & 6 & 1 & 1 & 3 & 1 & 0 \\
Group 2 & $6-11$ & 18 & 2 & 3 & 6 & 5 & 2 \\
Group 3 & $12-14$ & 6 & 1 & 0 & 2 & 1 & 2 \\
Group 4 & $21-22$ & 2 & 0 & 0 & 0 & 1 & 1 \\
Total & & 32 & 4 & 4 & 11 & 8 & 5 \\
\hline
\end{tabular}


As seen above, parental perception of skills developed by children differs. In some children, reported perception matches what is to be expected according to the developmental stage, while in others, there is no such relationship to it. However, in order to determine whether these differences were statistically significant, a Kruskall-Wallis test by age group was conducted. Statistically significant differences were only found in parental perception of self-care $\left(\chi^{2}=14.54\right.$, $d f=3, p<0.05)$. By conducting an adjusted Mann-Whitney $U$ test, such differences could be discerned in three pairs of groups: 1 and $2(\mathrm{Z}=-2.73, p<0.05), 1$ and $3(\mathrm{Z}=-3.10, p<0.05)$, and 2 and $3(\mathrm{Z}=-2.39, p<0.05)$. Parental perception in Group $1(M=42.33, S D=6.95)$ was lower than in Group $2(M=62.67$, $S D=14.52)$, which was in turn lower than in Group $3(M=77.50, S D=10.06)$. In fact, most parents in Group 1 perceived that their children are not capable of self-care, while in Group 2 and Group 3 this perception changes positively, with most parents (55.5\%, and $83.3 \%$ respectively) reporting that their children have developed self-care skills. That is, as children increase in age, the development of more self-care skills is perceived by parents.

As highlighted above, during transition processes from one developmental stage to another, language and social skills development and academic achievements are essential to a successful transition. This is especially relevant for children with ASD. Consequently, in this study, investigating parental perception was considered important not only concerning the development of multiple skills in their children, but also as to how the elements required to transition between different developmental stages were perceived. In the results below, perception reported by parents regarding the transition process of their children with ASD is shown and analyzed from different angles related to independence, educational aspirations, school experience, social impact, and the future.

In the dependence area, most parents (24) reported that they believed their children with ASD required to be assisted by them or other people to perform everyday activities. Only 3 of them perceived that their children can independently do activities such as preparing food, respecting hours of sleep, managing time and money, and behavioral self-regulation. With regard of educational aspirations (Table 5), most parents were identified to have low expectations that their children can continue education up to certain milestones. Only 5 of them reported having high aspirations regarding school transition for their children,

Table 5. Parent-perceived educational aspirations by children age group.

\begin{tabular}{cccccccc}
\hline & $\begin{array}{c}\text { Age of children } \\
\text { with ASD }\end{array}$ & $\mathrm{n}$ & Never & Seldom & Sometimes & $\begin{array}{c}\text { Most of } \\
\text { the time }\end{array}$ & Always \\
\hline Group 1 & $3-5$ & 6 & 1 & 1 & 2 & 1 & 1 \\
Group 2 & $6-11$ & 18 & 4 & 3 & 5 & 4 & 2 \\
Group 3 & $12-14$ & 6 & 1 & 1 & 2 & 1 & 1 \\
Group 4 & $21-22$ & 2 & 1 & 0 & 0 & 0 & 1 \\
Total & & 32 & 7 & 5 & 9 & 6 & 5 \\
\hline
\end{tabular}


because even if schoolwork may be complicated, parents believed their children could complete elementary school, middle school, or a technical degree. Some of them even believed their children may be able to go to college and get a good job.

Regarding parental perception of school experience of their children with ASD, the environment that children experience must be contextualized. Only 11 of 32 parents reported that their children have support from a supervising teacher most of the time; 18 parents reported that their children do not have any kind of additional support, and 3 parents reported that their children do not go to school. In summary, most children attended classes with a class teacher in a regular school. Parental perception of school experience of children was analyzed in two areas: activities a child does as per school requirements (from carrying backpacks, and independent activities in the classroom, to homework), and interactions with other school community members, including teachers and classmates. The elements that were analyzed in this environment included acceptance by classmates, support during classes, sympathy and care, friendship, and support from group teachers. In this sense only 6 parents reported that their children were prepared to meet school demands, and the school setting was prepared to accommodate the children's needs. On the contrary, 17 parents reported that in-classroom and school experiences were not favorable to a successful school transition. Consequently, the school setting in Mexico for children with ASD still requires more awareness about transition issues in different grades and levels of education.

The parental perception of social impact on their children's transition process it is important to note that 15 parents believed there does exist a social impact due to a child's disability, which results in life changes for all family members, as the child will always have special needs. In general, parents felt poorly supported, and showed confusion and anxiety about the skills their children may develop to meet social and academic demands during different developmental stages. Only 9 parents considered that no social impact was hindering their children's transition process. In general, parents try to prepare their children for the future, but their perception of their children with ASD is influenced by fears about their children's ability to independently do activities, such as traveling, making a living, living on their own, or even being in a couple. 17 parents reported that the future will be complicated, or even that their children will never be able to perform activities in a way that will make them independent from parents. In fact, only 8 parents reported having expectations that their children will achieve autonomy and happiness in the future.

Transition from one developmental stage to the next in children with ASD is accompanied by the development of different skills that allow them to face multiple challenges in every stage. In order to discern differences in parental perception of transition by children age group, a Kruskal-Wallis test was conducted. No statistically significant differences were found in any area: independence $\left(\chi^{2}\right.$ $=6.43, d f=3, p>0.05)$, educational aspirations $\left(\chi^{2}=0.77, d f=3, p>0.05\right)$, 
school experience $\left(\chi^{2}=5.87, d f=3, p>0.05\right)$, social impact $\left(\chi^{2}=1.37, d f=3, p>\right.$ $0.05)$, or expectations for the future $\left(\chi^{2}=1.55, d f=3, p>0.05\right)$.

Based on results above, it was deemed important to investigate, by means of a Spearman's correlation, whether there existed a statistically significant correlation between the parental perception of skills development in their children with ASD, and the elements and activities parents thought their children performed during transition processes.

Table 6 shows that parental perception of dependence in their children was negatively correlated in a statistically moderate-significant way, at 0.01 , with perceived skills in children. This implies that parents perceived lower development of language $(r=-0.535)$, routine $(r=-0.569)$, academic $(r=-0.599)$, emotional $(r=-0.680)$, social $(r=-0.587)$, and personal $(r=-0.509)$ skills, while also perceiving higher dependence in their children with ASD.

On the other hand, a positive statistically moderate-significant difference was found at 0.05 between perceived-performance in language skills $(r=0.382)$ and academic activities $(r=0.650)$, and the parental perception of children's educational aspirations. That is, when parents report an adequate use of language and academic skills, they believe their children can achieve a successful transition to different school grades and maintain appropriate interactions with teachers and peers. A positive moderate-significant correlation between parental perception of school experience of their children with ASD-especially peer relationships, use of technology, and school activities organization-and parental perception of the development of routine $(r=0.381)$, academic $(r=.488)$, social $(r=0.386)$, and self-care $(r=0.412)$ skills was observed. Parental perception of the future, mainly what parents believed will happen when their children grow older, is shown to be positively correlated with the development of routine $(r=0.357)$, academic $(r=0.527)$, emotional $(r=0.420)$, and social $(r=0.437)$ skills. That is, as parents perceive that their children have developed these skills, parents will believe in a better future for their children.

Table 6. Correlation between parent-perceived skills and transition activities in their children.

\begin{tabular}{|c|c|c|c|c|c|c|}
\hline \multirow{2}{*}{ Activities } & \multicolumn{6}{|c|}{ Skills } \\
\hline & 1) Language & 2) Routine & 3) Academic & 4) Emotional & 5) Social & 6) Personal \\
\hline 1) Dependent & $-0.535^{\star *}$ & $-0.569^{\star *}$ & $-0.599^{* *}$ & -0.680 & $-0.587^{\star *}$ & $-0.509^{\star *}$ \\
\hline $\begin{array}{l}\text { 2) Educational } \\
\text { aspirations }\end{array}$ & $0.382^{*}$ & & $0.650^{\star *}$ & & & \\
\hline $\begin{array}{l}\text { 3) School } \\
\text { experience }\end{array}$ & & $0.381^{\star}$ & $0.488^{\star *}$ & & $0.386^{\star}$ & $0.412^{*}$ \\
\hline 4) Social impact & & & & & & \\
\hline 5) Future & & $0.357^{\star}$ & $0.527^{\star *}$ & $0.420^{*}$ & $0.437^{\star}$ & \\
\hline
\end{tabular}

${ }^{*}$ Correlations are significant at $0.01 .{ }^{*}$ Correlations are significant at 0.05 . 
Finally, it was interesting noting that parental perception of social impact as related to the perception of transition processes, was the only perception that was not correlated with skills development in children, especially because the perception of social impact relies in child's disability. Although social inclusion may change, both in the nuclear family and the extended family settings, this was not perceived as being related to development of language skills, routine, and academic skills, or emotional, social, and personal skills.

\section{Discussion}

Transition from one developmental stage to another implies the deployment of a series of skills that allow individuals to face challenges and adjust under various circumstances. This is especially relevant for children, teens, and youth with ASD, as well as their parents as primary caregivers. This study overall observed that parental perception of multiple skills in children with ASD across developmental stages is low. Parents reported that their children, regardless of age, exhibited poor ability to communicate, as well as to adequately understand and use words, which hinders emotional expressiveness - children are not able to control or appropriately express emotions. This also influences poor performance in social skills. Parents identify their children as not possessing the ability to exhibit appropriate behaviors in social contexts, such as family and friends.

Since parents coincide in communication, emotional expressiveness, and social skills when reporting poor performance, these findings are in line with results from studies conducted by De la Iglesia and Olivar (2007), which found that children with ASD may possess more skills related to formal components of language, including phonology, morphology, and syntax, but have more deficits in components related to the social use of language, such as pragmatics. Martos-Pérez and Llorente-Comí (2013) explain that these deficits in pragmatic skills implies a lack of participation of children with ASD in dynamic, flexible, and reciprocal linguistic interactions, which may result in inappropriate social behavior. Moreover, Baixaulli-Fortea, Roselló-Miranda, Berenguer-Forner, Colomer-Diago, and Grau-Sevilla (2017) suggest that these deficits in communication in children with ASD cause social exclusion, hindering the quality of life not only for the children but also for their families. Parental perception reports are in line with results obtained by Naranjo, Becerra, Díaz, and Peralvo (2018), which suggest that children's language impairments, both in understanding and expressing relevant concepts, influence interpersonal communication.

Likewise, most parents reported that their children are not fully able to master habits and organization and are not provided with enough support to do everyday activities. However, some parents reported perceiving that children gain more maturity and develop certain habits as they grow older; however, parents report that children never fully develop these skills. Skills related to self-care, including personal hygiene and eating activities, were perceived by most parents as increasing over the years together with skills development and increase in age. In 
the same line, Goyoaga (2017) reports that the development of daily skills poses a challenge for children with or without ASD, but for the former, it can be impossible to overcome. This study observed that when parents perceive more habits development, it is probably because habits are constantly instilled at home.

Regarding school activities, most parents perceived that despite going to school, children do not do academic work typical of their grade level. This is in line with reports by Calderón, Reza, Lamingo, Loaiza, and Neira (2018) suggesting that teachers are not familiarized with ASD. This demonstrates the need for training in applying methodological strategies that allow teachers to improve the learning and teaching process for the population with ASD, especially since most parents reported that their children go to regular schools and do not have a supervising teacher. This has been observed in other studies, in which parents reported an incomplete school inclusion of their children with ASD (Adreon \& Stella, 2001; Makin et al., 2017; Mandy et al., 2016; Rea-Amaya \& Acle-Tomasini, 2017b).

Regarding the transition of children with ASD between different developmental stages, parents believe that their children are dependent and will need assistance from them or other people to do daily activities. However, some parents report that their children exhibit some elements required to transition, especially self-care activities. The dynamic relationship between dependence and independence, as perceived by parents, with regard to the activities their children are able to perform, is in line with observations by Rea-Amaya, and Acle-Tomasini (2017b), which show that parents reported self-efficacy to promote a better way to face their children's disability and overvalue what children could and could not achieve.

School experience as perceived by parents shows that children have globally developed in the school environment, since they can now do some activities, such as homework and exercises, and they are somewhat provided with support from peers and teachers. However, parents know that learning does not matches school grade level expectations, and this results in having low educational aspirations, and expecting children to continue up to a certain level of education. These findings are in line with results from other studies conducted worldwide, reporting that the higher the level of education, the less successful transition is (Adreon \& Stella, 2001; Makin et al. 2017; Miller-Warren, 2016). In Mexico, parents of children with ASD report that, in the school setting, teachers are not prepared to assist children with ASD at any level of education (Rea-Amaya \& Acle-Tomasini, 2017b), which is an area of opportunity.

Regarding the social impact of having a child with ASD, most parents believe that it is life changing for family members, since children will always have special needs. This has been reported in many studies, such as those conducted by Begeer et al. (2017), Cuervo (2019), Makin, Hill, \& Pellicano (2017), Mandy et al. (2016), Miller-Warren (2016), Sproston, Sedgewick, \& Crane (2017), Weiss et al. (2014), and Wehman et al. (2014), which suggest that parents face difficulties 
and big challenges in each transition stage, feel poorly supported, and exhibit confusion and anxiety about the skills that their children may develop to manage meeting academic and social demands. Rea-Amaya, Acle-Tomasini, \& Ordaz-Villegas (2017), however, suggest that resilience-related personal factors in parents may help them better deal with their children's disabilities.

Regarding how parents perceive their children's future, in this study only 8 parents reported to believe that their children with ASD will be able to organize financial life, travel, have a partner. Preoccupation about the future and this perception of it not being very promising may be associated with deficits in skills development and the awareness of children's dependence, both for skills development and transition-required elements. Depending on the child's stage of development, parents express different expectations that either match their children's actual development or the parental perception itself. Overall, most parents reported a low perception of skills in their children, which in turn restricts children's prospects of a promising future. Acle-Tomasini (2012) highlights that how parents face adverse stimuli and react to disability can place them in a situation of permanent adversity, if they do not manage to find favorable ways to contribute to the adjustment and inclusion of their children with ASD.

\section{Conclusion}

It is important to highlight that most of participants are aware of their autistic children abilities specially in self-care skills, but they also perceived their lack of development in other areas as communication, emotional expressiveness and social skills that restricted them in transition process to get independence in their lives, regardless of age. As the school is the primary setting where these skills must be at stake to achieve the transition at different academic levels, it is important to note that most of parents recognized that inside the school they found some limitations to promote their children transition school process; in particular, they pointed out a main difficulty regarding the lack of specialized teachers in the care of their autistic children and, consequently, there is no an adequate educational inclusion in the classroom.

As this study is based only on parental perception, in future research it will be important to assess both skills development and transition-required elements in their children with ASD; it is necessary to investigate whether children really possess and use these skills in the settings where they are required for transition.

\section{Acknowledgements}

A.C.R.A thanks the UNAM Postdoctoral Scholarships Program for granting support to do this research work.

G.A.T thanks the support granted by the UNAM Support Program for Technological Research and Innovation Projects, project number IN-303615.

We would also like to thank Yoallan Rivero for this English translation of the Spanish original. 


\section{Conflicts of Interest}

The authors declare no conflicts of interest regarding the publication of this paper.

\section{References}

Acle-Tomasini, G. (2012). Resilience in Special Education: A Regular School Experience. Barcelona: GEDISA-UNAM-FES Zaragoza.

Adreon, D., \& Stella, J. (2001). Transition to Middle and High School: Increasing the Success of Students with Asperger Syndrome. Intervention in School and Clinic, 36, 266-271. https://doi.org/10.1177/105345120103600502

Alverson, C., Lindstrom, L., \& Hirano, K. (2015). High School to College: Transition Experiences of Young Adults with Autism. Focus on Autism and Other Developmental Disabilities, 34, 52-64. https://doi.org/10.1177/1088357615611880

American Psychiatric Association (2014). Desk Reference to the Diagnostic Criteria from DSM-5. Spain: Editorial Médica Panamericana. https://doi.org/10.1176/appi.books.9780890425657

Baixaulli-Fortea, I., Roselló-Miranda, B., Berenguer-Forner, C., Colomer-Diago, C., \& Grau-Sevilla, M. (2017). Intervenciones para promover la comunicación social en niños con trastorno del espectro autista. Revista de Neurología, 64, 39-44. https://doi.org/10.33588/rn.64S01.2017013

Begeer, S., Ma, Y., Koot, H., Wierda, M., Van Beijsterveldt, C., Boomsma, D., \& Bartels, M. (2017). Brief Report: Influence of Gender and Age on Parent Reported Subjective Well-Being in Children with and without Autism. Research in Autism Spectrum Disorders, 35, 86-91. https://doi.org/10.1016/j.rasd.2016.11.004

Calderón, J., Reza, L., Lamingo, G., Loaiza, M., \& Neira, M. (2018). Autism Spectrum Disorders: Asperger Syndrome and the Effects on Academic Performance. Revista: Atlante Cuadernos de Educación y Desarrollo. https://www.eumed.net/rev/atlante/2018/09/trastornos-rendimiento-academico.html http://hdl.handle.net/20.500.11763/atlante1809trastornos-rendimiento-academico

Cuervo, G. (2019). Changes in the Spousal Link after the Birth of a Child with Autism. Trabajo Social, 21, 169-193. https://doi.org/10.15446/ts.v21n1.71426

De la Iglesia, M., \& Olivar, J. S. (2007). Training in Socio-Communication Skills in High-Functioning Autism Spectrum Disorders. Revista de Psicopatología y Psicología Clínica, 12, 33-42. https://doi.org/10.5944/rppc.vol.12.num.1.2007.4032

Dijkhuis, R., Ziermans, T., Van Rijn, S., Staal, W., \& Swaab, H. (2016). Self-Regulation and Quality of Life in High-Functioning Young Adults with Autism. Autism, 21, 896-906. https://doi.org/10.1177/1362361316655525

Fombonne, E., Marcin, C., Manero, A.C., Bruno, R., Diaz, C., Villalobos, M., Ramsay, K., \& Nealy, B. (2016). Prevalence of Autism Spectrum Disorders in Guanajuato, Mexico: The Leon Survey. Journal of Autism and Developmental Disorders, 46, 1669-1685. https://doi.org/10.1007/s10803-016-2696-6

Goyoaga, E. (2017). A Proposal for an Intervention for Social and Daily Living Skills Development in a Child with ASD. Master's Thesis, La Rioja: International University of La Rioja School of Education.

Jurado de los Santos, P., \& Bernal, D. (2013). El proceso de transición a la vida adulta de los jovenes con trastorno del espectro autista: Análisis de la planificación centrado en la persona. Educar, 49, 323-339. https://doi.org/10.5565/rev/educar.423 
Kerlinger, N., \& Lee, B. (2002). Foundations of Behavioral Research (4th ed.). Mexico: McGraw-Hill.

King, G. A., Zwaigenbaum, L., King, S., Baxter, D., Rosenbaum, P., \& Bates, A. (2006). A Qualitative Investigation of Changes in the Belief Systems of Families of Children with Autism or Down Syndrome. Child: Care, Health and Development, 32, 353-369. https://doi.org/10.1111/j.1365-2214.2006.00571.x

Makin, C., Hill, V., \& Pellicano, E. (2017). The Primary-to-Secondary School Transition for Children on the Autism Spectrum: A Multi-Informant Mixed-Methods Study. Autism \& Developmental Language Impairments, 2, 1-18. https://doi.org/10.1177/2396941516684834

Mandy, W., Murin, M., Baykaner, O., Staunton, S., Hellriegel, J., Anderson, S., \& Skuse, D. (2016). The Transition from Primary to Secondary School in Mainstream Education for Children with Autism Spectrum Disorder. Autism, 20, 5-13.

https://doi.org/10.1177/1362361314562616

Martos-Pérez, J., \& Llorente-Comí, M. (2013). Treatment of Autism Spectrum Disorders: Where Understanding Meets Evidence-Based Practice. Revista de Neurología, 57, 185-191. https://doi.org/10.33588/rn.57S01.2013264

Masten, A., \& Powell, J. (2007). A Resilience Framework for Research, Policy and Practice. In S. Luthar (Ed.), Resilience and Vulnerability. Adaptation in the Context of Childhood Adversities (pp. 1-25). Cambridge: University Cambridge Press. https://doi.org/10.1017/CBO9780511615788.003

Miller-Warren, V. (2016). Parental Insights on the Effects of the Secondary Transition Planning Process on the Postsecondary Outcomes of Graduates with Disabilities. Rural Special Education Quarterly, 35, 31-36. https://doi.org/10.1177/875687051603500105

Naranjo, M., Becerra, E., Díaz, R., \& Peralvo, G. (2018). A Communication Model for Early Language Development in Autistic Children. Retos de la Ciencia, 2, 35-46.

Quint, E. (2014). Menstrual and Reproductive Issues in Adolescents with Physical and Developmental Disabilities. Obstetrics \& Gynecology, 124, 367-375. https://doi.org/10.1097/AOG.0000000000000387

Quintero, N., \& McIntyre, L. (2011). Kindergarten Transition Preparation: A Comparison of Teacher and Parent Practices for Children with Autism and Other Developmental Disabilities. Early Childhood Education Journal, 38, 411-420. https://doi.org/10.1007/s10643-010-0427-8

Rea-Amaya, A., \& Acle-Tomasini, G. (2016). Perception of Skills in Children with Autism Spectrum Disorders Scale-Parent Version.

Rea-Amaya, A., \& Acle-Tomasini, G. (2017a). Perception of Transition-Related Elements in Children with Autism Spectrum Disorders Scale-Parent Version.

Rea-Amaya, A., \& Acle-Tomasini, G. (2017b). Vulnerability Situations and Resilient Strategies from Parents of Children with an Autism Spectrum Disorder (ASD). Revista Cocar, 11, 8-18.

Rea-Amaya, A., Acle-Tomasini, G., \& Ordaz-Villegas, G. (2017). Resilience Potential of Autistic Children's Parents and Its Relationship to Family Functioning and Acceptance of Disability. British Journal of Education, Society \& Behavioural Science, 20, 1-16. https://doi.org/10.9734/BJESBS/2017/32522

Shaughnessy, J., Zechmeister, E., \& Zechmeister, J. (2007). Research Methods in Psychol$\operatorname{ogy}$ (7th ed.). Mexico: McGraw-Hill.

Sproston, K., Sedgewick, F., \& Crane, L. (2017). Autistic Girls and School Exclusion: Perspectives of Students and Their Parents. Autism \& Developmental Language Im- 
pairments, 2, 1-14. https://doi.org/10.1177/2396941517706172

Stoner, J., Angell, M., House, J., \& Bock, S. (2007). Transitions: Perspectives from Parents of Young Children with Autism Spectrum Disorders (ASD). Journal of Developmental Physical Disabilities, 19, 23-39. https://doi.org/10.1007/s10882-007-9034-Z

Tobin, H., Staunton, S., Mandy, W. P. L. et al. (2012). A Qualitative Examination of Parental Experience of the Transition to Mainstream Secondary School for Children with an Autism Spectrum Disorder. Educational and Child Psychology, 29, 75-85.

Wehman, P., Schall, C., Carr, S., Targett, P., West, M., \& Cifu, G. (2014). Transition from School to Adulthood for Youth with Autism Spectrum Disorder: What We Know and What We Need to Know. Journal of Disability Policy Studies, 25, 30-40. https://doi.org/10.1177/1044207313518071

Wei, X., Wagner, M., Hudson, L., Yu, J., \& Shattuck, P. (2015). Transition to Adulthood: Employment, Education, and Disengagement in Individuals with Autism Spectrum Disorders. Emerging Adulthood, 3, 37-45. https://doi.org/10.1177/2167696814534417

Weiss, J., Wingsiong, A., \& Lunsky, Y. (2014). Defining Crisis in Families of Individuals with Autism Spectrum Disorders. Autism, 18, 985-995.

https://doi.org/10.1177/1362361313508024

Welchons, L., \& McIntyre, L. (2015). The Transition to Kindergarten for Children with and without Disabilities: An Investigation of Parent and Teacher Concerns and Involvement. Topics in Early Childhood Special Education, 35, 52-62. https://doi.org/10.1177/0271121414523141

WHO (2017). Autism Spectrum Disorder. World Health Organization http://www.who.int/mediacentre/factsheets/autism-spectrum-disorders/es 